\title{
Transient Stability Improvement of IEEE 9 Bus System Using Power World Simulator
}

\author{
Ramandeep Kaur ${ }^{1}$, Divesh Kumar ${ }^{2}$ \\ ${ }^{1,2}$ Department of Electrical Engineering, Bhai Gurdas Institue of Engineering and Technology, Sangrur, India
}

\begin{abstract}
The improvement of transient stability of power system was one of the most challenging research areas in power engineer.The main aim of this paper was transient stability analysis and improvement of IEEE 9 bus system. These studies were computed using POWER WORLD SIMULATOR. The IEEE 9 bus system was modelled in power world simulator and load flow studies were performed to determine pre-fault conditions in the system using Newton-Raphson method. The transient stability analysis was carried out using Runga method during three-phase balanced fault. For the improvement transient stability, the general methods adopted were fast acting exciters, FACT devices and addition of parallel transmission line. These techniques play an important role in improving the transient stability, increasing transmission capacity and damping low frequency oscillations.
\end{abstract}

Keywords- Transient stability, power system stability, three-phase fault, FACTS, Power world simulator, steady state.

\section{INTRODUCTION}

Now-a-days, it has become a necessity to maintain synchronism because the system is expanding dayby-day and these results in installation of larger machines. Due to this, transient disturbances are increasing continuously in power system. The transient disturbances are caused by the changes in the load, switching operations, faults and loss excitations. Thus, it is very important to regain synchronism or equilibrium after disturbances in the electrical utilities. Hence, thorough analysis of transient stability is required to reduce problems such as blackouts, loss of synchronism, etc.

The term stability refers to maintenance of synchronism and stability limit refers to maximum power flow possible in the system or a part of system at which system is operating with stability. Power system stability is the property of power system that enables it to remains in a state of equilibrium under normal operating conditions and toregain equilibrium after being subjected to disturbances.

Power system stability can be broadly grouped into steady state stability, transient stability and dynamic stability. Steady state stability is the capability of an electric power system to maintain synchronism between machines when small slow disturbance occurs. Dynamic stability is the ability of a power system to remain in synchronism after the initial swing until the system has settled down to the new steady state equilibrium conditions.

In this paper, the main emphasis is given to transient stability analysis of system and its improvement.. Transient stability is the ability of system to remain in synchronism during the period of disturbance and prior to the time that the governors can act. The transient stability analysis is carried out for a short time period that will be equal to the time of one swing. This analysis is carried out to determine whether the system losses stability during the first swing or not.

In this paper, Transient stability analysis is performed with the help of three-phase balanced fault.A fault which gives rise to equal fault currents in the lines with 120 degree displacement is known as three phase fault or symmetrical fault. Faults could happen when a phase establishes a connection with another phase, lightning, insulation deterioration, wind damage, trees falling across lines, etc.

The other objective of this paper that is improvement of IEEE 9 bus system is carried out using SVC, exciters and addition of parallel transmission line by Runga method. Static Var Compensators are used to improve voltage and reactive power conditions in AC systems. It also 
decreases oscillations in power system. The effectiveness of this controller depends on its optimal location and proper signal selection in the power system network.

The fast acting exciters used also decrease oscillations in the system. The amount of kinetic energy gained by the generators during a fault is directly proportional to the fault duration, the quicker the fault is cleared, the less disturbance it causes.

The series inductive reactances of transmission network are primary determinants of stability limits. The reduction of reactances of various elements of the transmission network improves transient stability by increasing post fault synchronizing power transfer. This can be achieved by addition of parallel transmission lines in the system.

To analyse swing behaviour of system it is solved by Runga method. Swing equation is the electromechanical equation describing relative emotion of the rotor load angle $(\delta)$ with respect to the stator field as a function of time is known as Swing equation. In most disturbances, linearization is not per-missile and the nonlinear swing equation must be solved because oscillations are of such magnitude.

Power flow analysis is called the backbone of power system analysis. Transient stability analysis of system fault analysis and its improvement is one of the basic problems in power system engineering.

The single line diagram of IEEE 9 bus model is shown in figure1:

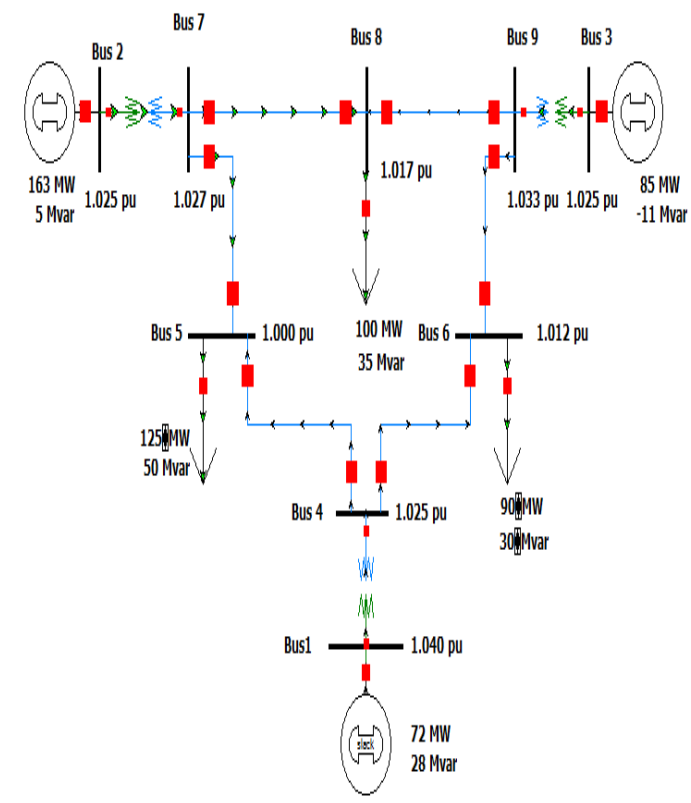

Fig.1. IEEE 9 BUS MODEL in power world simulator

\section{PROBLEM FORMULATION}

\section{A. Power Flow Studies}

In transient stability studies, it is necessary to have the knowledge of pre-fault voltages magnitudes. The main information obtained from the power flow study comprises of magnitudes and phase angles of bus voltages, real and reactive powers on transmission lines, real and reactive powers at generator buses, other variables being specified. The pre-fault conditions can be obtained from results of load flow studies by the Newton-Raphson iteration method.

The Newton-Raphson method is the practical method of load flow solution of large power networks. Convergence is not affected by the choice of slack bus. This method begins with initial guesses of all unknown variables such as voltage magnitude and angles at load buses and voltage angles at generator buses. Next, a Taylor Series is written, with the higher order terms ignored, for each of the power balance equations included in the system of equations.

We first consider the presence of PQ buses only apart from a slack bus.

For an ith bus, $\mathrm{Pi}=\sum_{k=1}^{n}|V i||V k||Y i k| \cos (\theta i k+\delta k-\delta i)=$
$\operatorname{Pi}(|V|, \delta)$

$\mathrm{Qi}=\sum_{k=1}^{n}|V i||V k||Y i k| \sin (\theta i k+\delta k-\delta i)=$ $Q i(|V|, \delta)$

i.e., both real and reactive powers are functions of $(|\mathrm{V}|, \delta)$, where

$|\mathrm{V}|=\left(\left|\mathrm{V}_{1}\right|, \ldots,\left|\mathrm{V}_{\mathrm{n}}\right|^{\mathrm{T}}\right) \delta=\left(\boldsymbol{\delta}_{1, \ldots,}, \boldsymbol{\delta}_{\mathrm{n}}\right)^{\mathrm{T}}$

We write

$\operatorname{Pi}(|\mathrm{V}|)=,\operatorname{Pi}(\mathrm{x})$

$\mathrm{Qi}(|\mathrm{V}|)=,\mathrm{Qi}(\mathrm{x})$

Where,

$\mathrm{x}=[\boldsymbol{\delta} /|\mathrm{V}|]$

Let Pi and Qi be the scheduled powers at the load buses. In the course of iteration $\mathrm{x}$ should tend to that value which makes

$\mathrm{Pi}-\mathrm{Pi}(\mathrm{x})=0$ and $\mathrm{Qi}-\mathrm{Qi}(\mathrm{x})=0$

Writing equation (3) for all load buses, we get its matrix form 
$\mathrm{f}(\mathrm{x})=\left[\begin{array}{l}P(\text { scheduled })-P(x) \\ Q(\text { scheduled })-Q(x)\end{array}\right]=\left[\begin{array}{l}\Delta P(x) \\ \Delta Q(x)\end{array}\right]=0$

At the slack bus, $\mathrm{P}_{1}$ and $\mathrm{Q}_{1}$ are unspecified.

Therefore, the values $\mathrm{P}_{1}(\mathrm{x})$ and $\mathrm{Q}_{1}(\mathrm{x})$ do not enter into equation (3) and hence (4). Thus, $x$ is a $2(n-1)$ vector ( $n-1$ load buses), with each element function of $(n-1)$ variables given by the vector $x=[\boldsymbol{\delta} /|\mathrm{V}|]$

We can write,

$\mathrm{f}(\mathrm{x})=\left[\begin{array}{l}\Delta P(x) \\ \Delta Q(x)\end{array}\right]=\left[\begin{array}{l}-J 11(x)-J 12(x) \\ -J 21(x 1)-J 22(x)\end{array}\right]\left[\begin{array}{c}\Delta \delta \\ \Delta|V|\end{array}\right]$

Where, $\Delta \boldsymbol{\delta}=\left(\Delta \boldsymbol{\delta}_{2},{ }^{,},, \Delta \boldsymbol{\delta} \mathrm{n}\right)^{\mathrm{T}}$

$\Delta|\mathrm{V}|=\left(\Delta\left|\mathrm{V}_{2}\right| \ldots \Delta|\mathrm{Vn}|\right)^{\mathrm{T}}$

$\mathrm{J}(\mathrm{x})=\left[\begin{array}{l}-J 11(x)-J 12(x) \\ -J 21(x)-J 22(x)\end{array}\right](6)$

$\mathrm{J}(\mathrm{x})$ is the jacobian matrix, each $\mathrm{J}_{11}, \mathrm{~J}_{12}, \mathrm{~J}_{21}, \mathrm{~J}_{22}$ are $(n-1) \times(n-1)$ matrices.

$-\mathrm{J}_{11}(\mathrm{x})=\frac{\partial P(x)}{\partial \delta}$

$-\mathrm{J}_{12}(\mathrm{x})=\frac{\partial P(x)}{\partial|V|}$

$-\mathrm{J}_{21}(\mathrm{x})=\frac{\partial Q(x)}{\partial \delta}$

$-\mathrm{J}_{22}(\mathrm{x})=\frac{\partial Q(x)}{\partial|V|}$

The elements of $-\mathrm{J}_{11},-\mathrm{J}_{12}, \mathrm{~J}_{21},-\mathrm{J}_{22}$ are

$\frac{\partial P i(x)}{\partial \delta k}, \frac{\partial P i(x)}{\partial|V k|}, \frac{\partial Q i(x)}{\partial \delta k}, \frac{\partial Q i(x)}{\partial|V k|}$,

Where $\mathrm{i}=2 \ldots \mathrm{n} ; \mathrm{k}=2 \ldots \mathrm{n}$.

From equation (1) and (2), we have

$$
\begin{gathered}
\frac{\partial P i(x)}{\partial \delta k}=-|V i||V k||Y i k| \sin (\theta i k+\delta k-\delta i)(i \\
=k) \\
=\sum_{\substack{k=1 \\
k \neq i}}^{n}|V i||V k||Y i k| \sin (\theta i k+\delta k-\delta i)(i=k)
\end{gathered}
$$

$\frac{\partial P i(x)}{\partial|V k|}=|V i||Y i k| \cos (\theta i k+\delta k-\delta i)(i \neq k)(8)$

$$
\begin{aligned}
& =2|V i||Y i i| \cos \theta i i \\
& +\sum_{\substack{k=1 \\
k \neq i}}^{n}|V k||Y i k| \cos (\theta i k+\delta k \\
& -\delta i)(i=k) \\
& \frac{\partial Q i(x)}{\partial \delta k}=|V i||V k||Y i k| \sin (\theta i k+\delta k-\delta i)(i \\
& \neq k) \\
& =\sum_{\substack{k=1 \\
k \neq i}}^{n}|V i||V k||Y i k| \cos (\theta i k+\delta k-\delta i)(i= \\
& \text { k)(9) } \\
& \frac{\partial Q i(x)}{\partial|V k|}=|V i||Y i k| \sin (\theta i k+\delta k-\delta i)(i \neq k) \\
& =2|V i||Y i i| \sin \theta i i+\sum_{\substack{k=1 \\
k \neq i}}^{n}|V k||Y i k| \sin (\theta i k+ \\
& \delta k-\delta i) \quad(i=k)(10)
\end{aligned}
$$

An important observation can be made with respect to the elements of Jacobian matrix. If there is no connection between ith and kth bus, then Yik $=0$. The process continues until a stopping condition is met.

\section{B. Transient stability analysis}

Transient stability studies deals with the effect of large, sudden disturbances such as effect of large sudden outage of line, occurrence of fault, or the sudden application or removal of loads. To ensure that a system can with stand the transient condition following a disturbance, transient stability analysis should be performed.

Steps for transient stability analysis in POWER WORLD SIMULATOR:

Step 1: An IEEE- 9 bus system is taken. System model is implemented and executed in power world simulator and load flow is performed. The load flow analysis of 9 bus system is done with the help of Newton Raphson method.

Step 2: After load flow, the initial parameters of the system e.g. bus voltages, bus frequency, bus power angles, generator power angles are studied.

Step 3: A three-phase balanced fault is applied on transmission line with different clearing times and the results are taken in Power World Simulator using Runga.

Step 4: Improvement of IEEE 9 bus simulated model using Runga method in POWER WORLD SIMULATOR. 
TABLE 1. LINE PARAMETERS OF 9 BUS SYSTEM

\begin{tabular}{|c|c|c|c|}
\hline Line & Resistance(PU) & Reactance(PU) & Susceptence(PU) \\
\hline $1-4$ & 0.0000 & 0.0576 & 0.0000 \\
\hline $4-5$ & 0.0170 & 0.0920 & 0.1580 \\
\hline $5-6$ & 0.0390 & 0.1700 & 0.3580 \\
\hline $3-6$ & 0.0000 & 0.0586 & 0.0000 \\
\hline $6-7$ & 0.0119 & 0.1008 & 0.2090 \\
\hline $7-8$ & 0.0085 & 0.0720 & 0.1490 \\
\hline $8-2$ & 0.0000 & 0.0625 & 0.0000 \\
\hline $8-9$ & 0.0320 & 0.1610 & 0.3060 \\
\hline $9-4$ & 0.0100 & 0.0850 & 0.1760 \\
\hline
\end{tabular}

\section{Standard Parameters}

TABLE 2. MACHINE DATA OF 9 BUS SYSTEMS

\begin{tabular}{|l|l|l|l|}
\hline Parameters & M/C 1 & M/C 2 & M/C 3 \\
\hline H(sec) & 23.64 & 6.4 & 3.01 \\
\hline Xd(PU) & 0.146 & 0.8958 & 1.3125 \\
\hline X'd(PU) & 0.0608 & 0.1198 & 0.1813 \\
\hline Xq(PU) & 0.0969 & 0.8645 & 1.2578 \\
\hline X'q(PU) & 0.0969 & 0.1969 & 0.25 \\
\hline T'd0(PU) & 8.96 & 6.0 & 5.89 \\
\hline T'q0(PU) & 0.31 & 0.535 & 0.6 \\
& & & \\
\hline
\end{tabular}

\section{TABLE 3: EXCITER DATA OF 9 BUS SYSTEMS}

\begin{tabular}{|l|l|l|l|}
\hline Parameters & Exciter 1 & Exciter 2 & Exciter 3 \\
\hline $\mathrm{K}_{\mathrm{A}}$ & 20 & 20 & 20 \\
\hline $\mathrm{T}_{\mathrm{A}}(\mathrm{sec})$ & 0.2 & 0.2 & 0.2 \\
\hline $\mathrm{K}_{\mathrm{E}}$ & 1.0 & 1.0 & 1.0 \\
\hline $\mathrm{T}_{\mathrm{E}}(\mathrm{sec})$ & 0.314 & 0.314 & 0.314 \\
\hline $\mathrm{K}_{\mathrm{F}}$ & 0.063 & 0.063 & 0.063 \\
\hline $\mathrm{T}_{\mathrm{F}}(\mathrm{sec})$ & 0.35 & 0.35 & 0.35 \\
\hline
\end{tabular}

\section{RESULTS AND DISCUSSION}

The load flow analysis and transient stability for the standard IEEE-9 bus system are performed. The standard IEEE 9 bus system consists of 9 buses, 3 generators, 3 loads and 3 transformers. Table $4 \& 5$ shows load flow analysis carried out using NewtonRaphson method. Table 6 shows power angle with different clearing times by Runga method.
TABLE 4. POWER FLOW LIST OF IEEE 9 BUS SYSTEM

\begin{tabular}{|c|c|c|c|c|c|c|c|}
\hline $\begin{array}{l}\text { Fro } \\
\text { m } \\
\text { Bus }\end{array}$ & $\begin{array}{l}\text { To } \\
\text { Bu } \\
\text { s }\end{array}$ & $\begin{array}{l}\text { Branch } \\
\text { Device } \\
\text { Type }\end{array}$ & $\begin{array}{l}\text { MW } \\
\text { Fro } \\
\text { m }\end{array}$ & $\begin{array}{l}\text { Mva } \\
\mathbf{r} \\
\text { Fro } \\
\mathbf{m}\end{array}$ & $\begin{array}{l}\text { MV } \\
\text { A } \\
\text { Fro } \\
\text { m }\end{array}$ & $\begin{array}{l}\text { MW } \\
\text { Loss }\end{array}$ & $\begin{array}{l}\text { Mva } \\
\mathbf{r} \\
\text { Loss }\end{array}$ \\
\hline 4 & 1 & $\begin{array}{l}\text { Transforme } \\
\mathrm{r}\end{array}$ & -72 & -24.8 & 75.8 & 0 & 3.15 \\
\hline 2 & 7 & $\begin{array}{l}\text { Transforme } \\
\mathrm{r}\end{array}$ & 163 & 4.9 & 163 & 0 & 15.8 \\
\hline 9 & 3 & $\begin{array}{l}\text { Transforme } \\
\mathrm{r}\end{array}$ & -85 & 15.6 & 86.4 & 0 & 4.1 \\
\hline 5 & 4 & Line & -43 & -39.6 & 58.5 & 0.3 & -16 \\
\hline 6 & 4 & Line & -28 & -16.9 & 32.9 & 0.1 & -16 \\
\hline 7 & 5 & Line & 84.2 & -10.1 & 84.8 & 2.2 & -21 \\
\hline 9 & 6 & Line & 63.3 & -17.8 & 65.7 & 1.5 & -31 \\
\hline 7 & 8 & Line & 78.8 & -0.8 & 78.9 & 0.5 & -12 \\
\hline 8 & 9 & Line & -22 & -23.6 & 32.1 & 0.1 & -21 \\
\hline
\end{tabular}

TABLE 5. BUS DATA OF IEEE 9 BUS MODEL

\begin{tabular}{|c|c|c|c|c|c|c|c|c|}
\hline Name & $\begin{array}{c}\text { Nom } \\
\mathrm{kV}\end{array}$ & $\begin{array}{c}\text { PU } \\
\text { Volt }\end{array}$ & $\begin{array}{c}\text { Volt } \\
(\mathrm{kV})\end{array}$ & $\begin{array}{c}\text { Angle } \\
(\text { Deg) }\end{array}$ & $\begin{array}{c}\text { Load } \\
\text { MW }\end{array}$ & $\begin{array}{c}\text { Load } \\
\text { Mvar }\end{array}$ & $\begin{array}{c}\text { Gen } \\
\text { MW }\end{array}$ & $\begin{array}{c}\text { Gen } \\
\text { Mvar }\end{array}$ \\
\hline 1 & 16.5 & 1.04 & 17.16 & 0 & & & 71.63 & 27.91 \\
\hline 2 & 18 & 1.03 & 18.45 & 9.35 & & & 163 & 4.9 \\
\hline 3 & 13.8 & 1.03 & 14.15 & 5.14 & & & 85 & $\begin{array}{c}- \\
11.45\end{array}$ \\
\hline 4 & 230 & 1.03 & 235.8 & -2.22 & & & & \\
\hline 5 & 230 & 1 & 229.9 & -3.68 & 125 & 50 & & \\
\hline 6 & 230 & 1.01 & 232.8 & -3.57 & 90 & 30 & & \\
\hline 7 & 230 & 1.03 & 236.2 & 3.8 & & & & \\
\hline 8 & 230 & 1.02 & 234 & 1.34 & 100 & 35 & & \\
\hline 9 & 230 & 1.03 & 237.5 & 2.44 & & & & \\
\hline
\end{tabular}

TABLE 6 POWER ANGLE WITH DIFFERENT CLEARING TIMES BY RUNGA METHOD

\begin{tabular}{|c|c|}
\hline Clearing Time (Sec) & $\begin{array}{c}\text { Angle(Runga Method) in } \\
\text { Degree }\end{array}$ \\
\hline 1.033 & 106.487 \\
\hline 1.05 & 109.063 \\
\hline 1.066 & 112.238 \\
\hline 1.083 & 116.237 \\
\hline
\end{tabular}

When three-phase balanced fault is applied on transmission line between bus 5 and 7, disturbances occurs in the system that results in power angle oscillations. When clearing time is $1.033 \mathrm{sec}$ or 2 cycles, the maximum angle difference is 106.487 degree and further, if clearing time is increased, it results in increase in maximum angle difference as 
shown in Table 4. This means system is going towards un-stability mode.

For the improvement transient stability, the general methods adopted were fast acting exciters, FACT devices and addition of parallel transmission line. These techniques play an important role in improving the transient stability, increasing transmission capacity and damping low frequency oscillations. Table 7, 8 and 9 shows comparison of power angle difference between with and without SVC, shows comparison of power angle difference between with and without parallel transmission lines and comparison of power angle between EXST4B and existing exciter.

TABLE 7. COMPARISON OF POWER ANGLE DIFFERENCE BETWEEN WITH AND WITHOUT SVC

\begin{tabular}{|c|c|c|}
\hline Cycles & $\begin{array}{c}\text { Max angle } \\
\text { difference } \\
\text { with } \\
\text { compensation } \\
\text { (degree) }\end{array}$ & $\begin{array}{c}\text { Max angle } \\
\text { difference } \\
\text { without } \\
\text { compensation } \\
\text { (degree) }\end{array}$ \\
\hline 2 & 105.119 & 106.487 \\
\hline 3 & 107.375 & 109.063 \\
\hline 4 & 110.199 & 112.238 \\
\hline 5 & 113.801 & 116.237 \\
\hline
\end{tabular}

TABLE 8. COMPARISON OF POWER ANGLE DIFFERENCE BETWEEN WITH AND WITHOUT PARALLEL TRANSMISSION LINE

\begin{tabular}{|c|c|c|}
\hline Cycles & $\begin{array}{c}\text { Max angle } \\
\text { difference } \\
\text { with parallel } \\
\text { line } \\
\text { (degree) }\end{array}$ & $\begin{array}{c}\text { Max angle } \\
\text { difference } \\
\text { without } \\
\text { parallel line } \\
\text { (degree) }\end{array}$ \\
\hline 2 & 71.34 & 106.488 \\
\hline 3 & 75.178 & 109.065 \\
\hline 4 & 79.145 & 112.24 \\
\hline 5 & 83.754 & 116.238 \\
\hline
\end{tabular}

TABLE 9 COMPARISON OF POWER ANGLE BETWEEN EXST4B AND EXISTING EXCITER

\begin{tabular}{|c|c|c|}
\hline Cycles & $\begin{array}{c}\text { EXST4B } \\
\text { Exciter }\end{array}$ & $\begin{array}{c}\text { Existing } \\
\text { Exciter }\end{array}$ \\
\hline 2 & 98.520 & 106.488 \\
\hline 3 & 99.394 & 109.065 \\
\hline 4 & 101.112 & 112.24 \\
\hline 5 & 103.680 & 116.238 \\
\hline
\end{tabular}

When SVC is used for improvement of IEEE 9 Bus model, it is found that the maximum angle difference is lesser with SVC than without SVC as shown in Table 7. The maximum angle difference can be decreased by addition of parallel transmission line on the system as depicted in Table 8 . Table 9 shows decrease in power angle by use of EXST4B exciter

\section{CONCLUSION}

This paper presents the transient stability analysis and its improvement using power world simulator. The effectiveness of shunt FACT devices such as SVC, addition of parallel transmission lines and exciters has been studied in improving the system stability with different loads. The load flow studies are also performed to determine prefault conditions. Hence, by proper modelling of system, it would be interesting to determine any other possible advantage of controllers in power system stability-studies.

\section{REFERENCES}

1. R. A. Naghizadeh, S. Jazebi, B. Vahidi, "Modeling hydro power plants and tuning hydro governors as an educational guideline," International Review on Modeling and Simulations (I.RE.MO.S.), Vol. 5, N. 4,(2012)

2. Vadim Slenduhhov, Jako Kilter, "Modeling and analysis of the synchronous generators excitation systems",Publication of Doctoral School of Energy and Geotechnology, Pärnu, (2013)

3. Sandeep Kaur, Dr. Raja Singh Khela,"Power system design \& stability analysis," international journal of advanced research in computer science and software engineering, Volume 4, Issue 1, (2014)

4. M.A Salam, M. A. Rashid, Q. M. Rahman and M. Rizon, "Transient stability analysis of a three machine nine bus power system network", Advance online publication, (2014)

5. Swaroop Kumar.Nallagalva, Mukesh Kumar Kirar, Dr.Ganga Agnihotri, "Transient Stability analysis of the IEEE 9-Bus electric power system", International Journal of Scientific Engineering and Technology, Volume No.1, Issue No.3, pp.: 161-166, ( 2012)

6. Ž. Eleschová, M. Smitková and A. Beláň, "Evaluation of power system transient stability and definition of the basic criterion", Internationals journal of energy, Issue 1, Vol. 4, (2010)

7. Tin Win Mon and Myo Myint Aung "Simulation of synchronous machine in stability study for power system", International Journal of Electrical and Computer Engineering 3:13, (2008)

8. Yaman C. Evrenosoglu, Hasan Dag,"Detailed Model for Power System Transient Stability Analysis".Journal of Engineering \& Computer Science IJECS-IJENS, Vol: 13 No:02, (2012)

9. H.T.Hassan, 2Usman Farooq Malik, 3Irfan Ahmad Khan, 4Talha Khalid, "Stability Improvement of Power System Using Thyristors Controlled Series Capacitor (TCSC)", 
10. Gundala Srinivasa Rao, Dr. A.Srujana, “Transient Stability Improvement of Multi-machine Power System Using Fuzzy Controlled TCSC" International Journal of Advancements in Research \& Technology",ISSN 22787763, Volume 1, Issue 2(2012) 